\title{
Pneumonia and Pandemic Influenza A H1N1 Virus Infection: A Review of the Literature
}

Servet Kayhan ${ }^{1 *}$, Halit Çınarka ${ }^{1}$, Aziz Gümüşs ${ }^{1}$ Ünal Şahin ${ }^{1}$

1. Department of Pulmonary Medicine, Recep Tayyip Erdogan University, Rize, Turkey

\begin{abstract}
Influenza viruses cause seasonal epidemics and occasional pandemics. On 18 March 2009, A novel swine origin influenza $A(H 1 N 1)$ virus was seen in Mexico, then a global outbreak of respiratory illness started. The new H1N1 virus usually attaches to tracheobronchial epithelial cells and the clinical picture ranges from transient lower respiratory tract infections to severe pneumonia leading to acute respiratory distress syndrome. The main complication is extension of viral infection to the alveoli that causes primary viral pneumonia. The most common radiologic findings are unilateral or bilateral ground-glass opacities and multifocal areas of consolidations Bacterial coinfections, particularly Streptococcus pneumoniae and Staphylococcus aureus, increase the severity of illness. Patients with underlying cardiopulmonary comorbid conditions, pregnancy and obesity appear to be at higher risk of severe pneumonia. The severe cases have required admission to intensive care units and needs to mechanical ventilation. H1N1 influenza virus is now in post-pandemic period; however, localized outbreaks of various magnitudes are being reported.
\end{abstract}

Keywords: H1N1; influenza; pandemic; pneumonia

\section{Introduction}

Swine flu or a novel swine-origin influenza A (H1N1) virus was first reported in Mexico in April 2009. The pandemic spread with the travellers throughout the world, by the start of human to human transmission $(1,2)$. In June 2009, the World Health Organization (WHO), raised the pandemic alert level to phase-6. Further investigations revealed that the novel swine origin influenza A (H1N1) virus represented a quadruple reassortment of one human, one avian and two swine strains and the antigenic shift of the virus occurred in pigs. The H1N1 pandemic moved into the postpandemic period in August 2010 and nearly 18,500 confirmed deaths have been reported globally (2).

\section{Corresponding author:}

Servet Kayhan

Department of Pulmonary Medicine, Recep Tayyip Erdogan University, Rize, Turkey

Fax number: +904642170364, Email: kayhanservet@gmail.com

Received: 13-07-2013 Accepted: 10-07-2013 Published: 07-01-2014

doi:10.7575/aiac.abcmed.v.2n.1p.2 
Influenza A viruses is a member of Orthomyxovirus family, with 16 subunits of hemagglutinin and 9 subunits of neuraminidase proteins used for antigenic subtyping The virus causes a very contagious respiratory tract infection. The H1N1 infections occurred mostly in children, females and young adults. Major complication of the infection is pneumonia that occurred by the extension of H1N1 virus to alveoli and sometimes bacterial coinfections, and once the virus causes respiratory failure, the mortality rate increases dramatically (2-4). Complications including pneumonia and acute respiratory distress syndrome occurred in some of the cases, especially those affected by comorbidities including obesity, pregnancy, diabetes mellitus, cardiopulmonary and neuropsychiatric diseases (3,5-7).

In this review, we briefly summarize the epidemiology, pathogenesis, clinical and radiological manifestations, risk factors, pulmonary involvements and management of the pneumonia related with pandemic influenza A (H1N1) virus infection based on the literature.

\section{EPIDEMIOLOGY}

Influenza A pandemics have occurred 3 times in the 20th century: Spanish flu (H1N1 in 1918) responsible for 50-100 million deaths, Asian flu (H2N2 in 1957) responsible for 1 million deaths, and Hong-Kong flu (H3N2 in 1968) responsible for 700,000 deaths worldwide. Influenza A (H1N1) reemerged in 1977 to periodically circulate concurrently with
H3N2 subtypes. Antigenic drift represents the minor changes in the structures of antigenic glycoproteins; hemagglutinin $(\mathrm{H})$ and neuraminidase $(\mathrm{N})$ of influenza virus and it is responsible for the seasonal epidemics each year. Influenza pandemics occur less frequently, as a result of major changes in antigenic structure (antigenic shift).

The epidemiologic investigations of pandemic Influenza (H1N1) 2009 virus infection indicated that children and young adults have had the highest attack rates and hospitalizations. $(8,9)$. In contrast to seasonal influenza, and the most hospitalizations due to pandemic infection was observed in young and healthy adults or adolescents $(8,9)$. The relative sparing of elderly patients is likely due to immunological memory of the individuals who exposed to a type of H1N1 virus similar to the 2009 pandemic strain previously (10-12). As an example, an analysis of 532 cases of 2009 pandemic $H 1 N 1$ influenza $A$ in the USA has revealed that $60 \%$ of the cases were seen in the patients younger than 18 years and that only a small amount (5\%) occurred in the patients elder than 50 years (12). Complications leading to hospitalization and possibly death occurred particularly in some of the subjects with underlying chronic cardiopulmonary disease, immunosuppressive states, pregnancy and post-partum states, diabetes mellitus, obesity and children with neurological disabilities $(1,5)$, (Table 1).

\section{TABLE 1: Risk factors for severe disease of pandemic (H1N1) 2009 virus infection}

- Infants and young children $<2$ years

- Pregnant women

- $\quad$ Chronic pulmonary disease (e.g. asthma, COPD)

- Chronic cardiac disease

- Metabolic disorders, mainly diabetes mellitus

- Chronic renal and hepatic and neurological conditions 
- Hemoglobinopathies, or immunosuppression (HIV infection, immunosuppressive

medication or malignancy)

- Children receiving chronic aspirin therapy

- Persons aged 65 years and older

- Obesity (particularly morbidly obesity, BMI $\geq 40$ )

In pandemic influenza A (H1N1), obesity (body mass index $\geq 30 \mathrm{~kg} / \mathrm{m}^{2}$ ) and morbid obesity (body mass index $\geq 40 \mathrm{~kg} / \mathrm{m}^{2}$ ) were found to be independent risk factors for severe disease and mortality (5). This particular susceptibility to respiratory infection may be the result of disturbances in ventilatory mechanics and in the immune system, and an increased risk of thrombosis (5).

Another important risk factor for severe disease was pregnancy. Pregnant patients have 4-5 times more likely to develop severe respiratory illness. As a consequence, the hospitalization rate was significantly higher among pregnant women pregnant women represented $6.4 \%$ of hospitalized cases and $4.3 \%$ of death during the 2009 H1N1 pandemic (13). Maternal obesity and smoking during pregnancy were also associated with hospital admission and more severe disease. Most of the hospitalized patients are children $(<2$ years of age), and those with chronic illness. Approximately $10-30 \%$ of all hospitalized patients have required admission to intensive care units (8). A case fatality rate of $0.45 \%$ has been reported for H1N1 infection (2). The mortality rates are high in the patients with respiratory failure changed between $17-28 \%$, these are also older patients having several comorbid conditions $(1,3)$.

\section{SYMPTOMS AND SIGNS}

Respiratory viruses account for $10 \%$ to $40 \%$ of community-acquired pneumonia (CAP) the most frequently encountered viruses in CAP are influenza $A$ and $B$, adenovirus, and respiratory syncytial virus (14). The key feature of the clinical presentation related to novel influenza A (H1N1) is a frequent association with pneumonia, compared with other viruses, and seasonal influenza. The incubation period of H1N1 is similar to that of seasonal flu. The spectrum of the disease is very large and it can be seen as a non-febrile, mild upper respiratory tract infection or a severe repiratory failure. Symptoms are high fever (typically $>38^{\circ} \mathrm{C}$ and suddenly risen), cough, sore throat, malaise, arthralgia, myalgia, headache, gastrointestinal symptoms such as nausea, vomiting and diarrhoea (15). Complicated or severe influenza presents with shortness of breath, hypoxia and radiological signs of pneumonia. Hospitalized patients were evaluated by Riquelme et al. and they reported that nearly $40 \%$ of them associated with viral pneumonia and $10-30 \%$ of them needed to ventilatory support in ICU (8). Exacerbation of underlying chronic respiratory disease (asthma, COPD), central nervous system involvement, renal failure, multiorgan failure, and septic shock are the other systemic complications (15). Lymphocytes count relatively decrease and this is a nonspecific hematologic finding of influenza $A$ (H1N1) pneumonia (16). Elevated number of leucocytes and neutrophils may show the bacterial coinfection and lymphopenia $1<$ $800 / \mathrm{mL}$ ) is generally associated with severe infection (16). High-dose corticosteroids treatment may increase the risk of invasive aspergillosis (17). The patients with H1N1 virus infection may come to emergency department, with a higher fever, lower systolic blood pressure, lower oxygen saturation level, and with a nonspecific laboratory findings such as leucopenia, relative lymphopenia, 
thrombocytopenia, hypokalemia, elevated serum transaminases and elevated creatine phosphokinase $(9,18,19)$.

\section{PATHOGENESIS, PATHOLOGIC IMMUNOLOGIC FEATURES}

AND

Influenza virus attaches to ciliated columnar epithelial cells of respiratory tract via its surface hemagglutinin antigens after an inhalation of virus containing droplets. Respiratory defense mechanisms such as mucociliary clearance, secretion of specific secretory IgA antibodies help to remove some of the virus particles. However, the defense mechanism is impaired in smokers and elderly people (20-22). If the virus attaches to epithelial cells then invasion and viral replication occurs, subsequently newer viruses infect the other epithelial cells, shut off the synthesis of critical proteins, and ultimately lead to host cell death (23). In patients with uncomplicated influenza, bronchoscopic examination typically reveals diffuse inflammation and edema in the airways and biopsy shows the lymphocytic infiltration and desquamation of the ciliated columnar epithelium (24). In patients with primary viral pneumonia, pathologic examinations showed necrotizing tracheobronchitis, ulceration of the bronchial mucosa, intraalveolar hemorrhage, infiltration of alveolar spaces with fluid, fibrin, and cellular exudates, and lining of the alveoli with acellular hyaline membranes (25-27). Autopsies from the patients with primary influenza pneumonia confirmed similar results including bilateral severe interstitial inflammation, diffuse alveolar damage, hemorrhagic pneumonitis and virus particles observed particularly in the peripheric areas of the lungs $(25,27)$. The lung damage in acute respiratory failure was most likely due to infection by the influenza virus.

Alveolar and respiratory epithelial invasion through the basement membrane, alveolar collapse by the loss of surfactant, secondary cytokine storm aiming to eradicate the virus are the possible mechanism of tissue damage in H1N1 virus pneumonia (27). This is followed by exudation of macromolecules from the circulation and at the end of these reactions hyaline membranes occur. Neutrophilic infiltration in the pulmonary parenchyma may show the coexistence of bacterial infection (28). A number of inflammatory cells including macrophages and lymphocytes are present around bronchioles and small vessels. IL-4, IL10 and iNOS expression is high in mononucleated cells (27). Immunological studies revealed that high plasma IL-6, IL-8 and MCP-1 levels are associated with intensive care admissions and pro-inflammatory cytokines IL6, IL-8, and TNFR-1 are associated with pneumonia (27).

\section{RADIOLOGIC FINDINGS}

Bilateral, symmetric, and multifocal areas of consolidation often associated with groundglass opacities are the predominant findings of influenza A H1N1 pneumonia and are often associated with a more severe clinical course $(6,7,29,30)$, (Table 2, Figure 1,2 and 3). Other rarer radiologic manifestations are pneumothorax, pneumomediastinum, and atelectasis which are mostly seen in the state of acute respiratory distress syndrome (30). Additional findings include small pleural fluids, cavitation, necrosis, and thickening of bronchial wall (30). The most frequent findings on high resolution computerized tomography findings were the thickening of the peribronchovascular space, followed by intralobular septa thickening, subpleural septa thickening, bronchiectasis, mosaic image of perfusion, lymphadenopathies, pulmonary condensation zones, fibrotic bands, atelectatic bands and posterior basal thickening $(31,32)$.

Figures: Computed tomography (CT) scans of the patients with confirmed primary influenza A H1N1 pneumonia from a late localized outbreak of influenza A H1N1 in eastern part of Black sea region, Rize, Turkey. 
Figure 1:A 24 year-old male patient with $38,5{ }^{\circ} \mathrm{C}$ fever, cough and mild dyspnea, CT scan reveals bilateral multifocal, subpleural consolidations, he recovered after oceltamivir treatment.

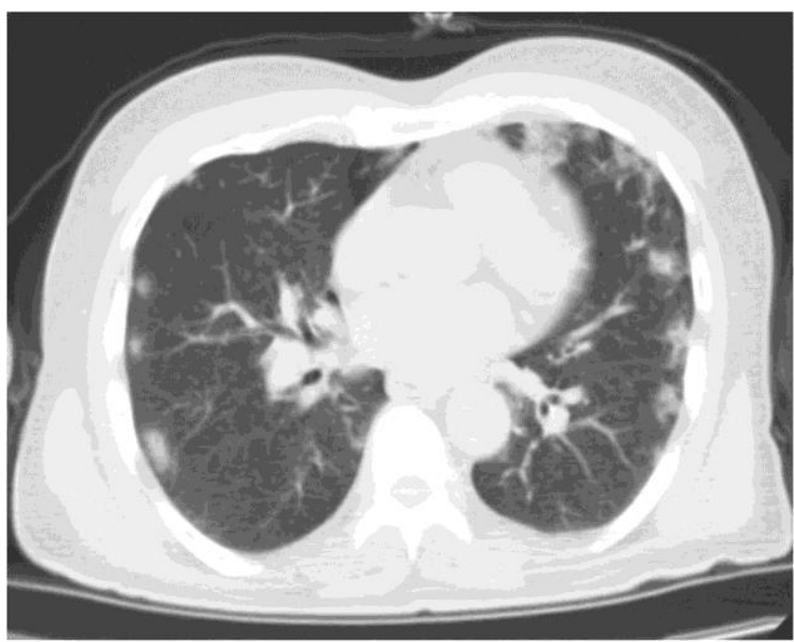

Figure 2: A 38 year-old, female patient admitted to emergency department with $38^{\circ} \mathrm{C}$ fever, cough, malaise, myalgia and dyspnea CT scan shows bilateral multifocal consolidations, and air-bronchograms in right lower lobe. She recovered completely after oceltamivir treatment.

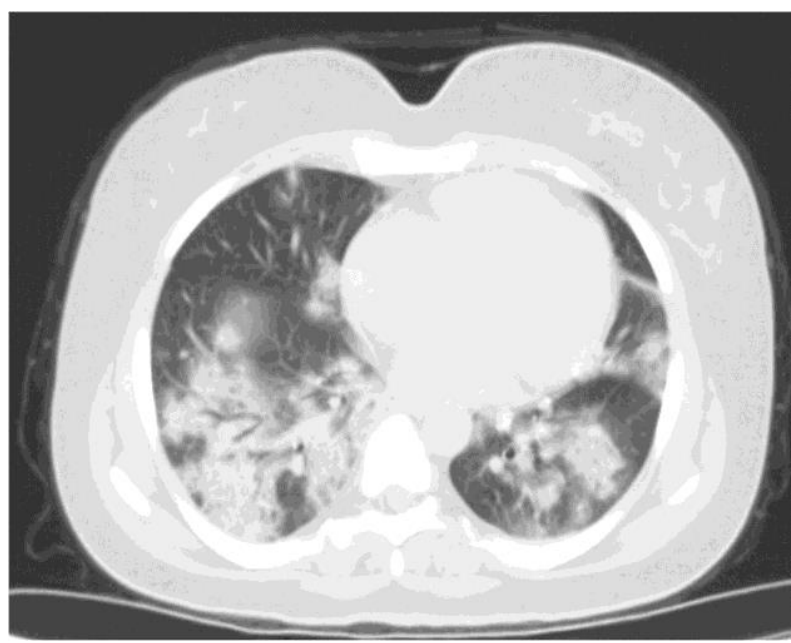

Figure 3: A 29 year-old female patient with obesity (BMI: $36,15 \mathrm{~kg} / \mathrm{m}^{2}$ ), $39{ }^{\circ} \mathrm{C}$ fever, severe dyspnea, she admitted to emergency department after 7 days from onset of symptoms and CT scan revealed bilateral multifocal ground glass appearence. She had a rapidly progressive pneumonia and respiratory failure leading to acute respiratory distress syndrome, needed intensive care having hypoxemia $\left(\mathrm{PaO}_{2} / \mathrm{FiO}_{2}<300 \mathrm{~mm} \mathrm{Hg}\right)$, invasive mechanical ventilation was performed but she died during the second day of ICU treatments.

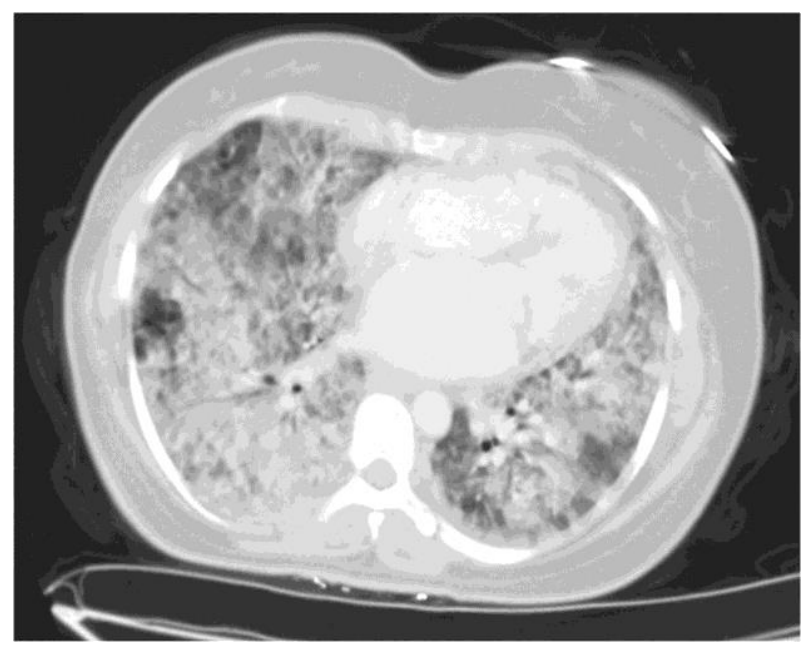

TABLE 2

Chest Computed Tomography Findings in Influenza A (H1N1) Pneumonia

Parenchymal findings

- Consolidation: Unilateral, bilateral, focal, multifocal, multifocal bilateral, subpleural, peribronchovascular, diffuse

- Ground-glass opacity: Unilateral, bilateral, focal, multifocal, multifocal bilateral, subpleural, peribronchovascular, diffuse

- Air-bronchograms, reticular pattern, nodular pattern, tree-in-bud appearence

- Atelectasis

- Cavitations and necrosis

- Thickenning of bronchial walls Pleural findings

- Pleural effusion, pneumothorax

Mediastinal findings

- Pneumomediastinum, lymphoadenopathy 


\section{COINFECTIONS AND COMPLICATIONS}

A lower respiratory tract involvement was seen from $19 \%$ to $50 \%$ of the H1N1 virus infection $(10,11,14)$. The impact of viral and bacterial coinfection was reported in several studies (14,33-35). As an example Marcos studied 181 patients with confirmed influenza A (H1N1), and $12 \%$ of them had coinfection with at least one or more respiratory viruses (33). It is found that the most common concomitant viruses were rhinovirus, enterovirus, coronavirus and parainfluenza virus. The existence of coinfections with the other viruses may cause a severe clinical illness and consequently a longer period of hospitalization. $(4,33,35)$. Bacterial coinfection has been reported with rates between $15-28 \%$ $(11,36-38)$. The commonest agent for a bacterial coinfection was $S$. pneumoniae, and followed by Mycoplasma pneumoniae, Staphylococcus aureus, Klebsiella pneumoniae, Moraxella catarrhalis, Pseudomonas aeruginosa, Streptococcus pyogenes, and Streptococcus agalactiae $(4,11,33,39)$. Geriatric patients and the presence of underlying comorbidities particularly have an increased risk for bacterial coinfections (4). Influenza virus usually causes transient lower respiratory tract infections, corresponding with virus attachment to tracheobronchial epithelial cells and patients recovers without any medical care. The main complication is extension of viral infection to the alveoli that causes primary viral pneumonia $(6,7)$. Bacterial coinfection was determined in lung tissue specimens from $29 \%$ of the patients with fatal cases of confirmed H1N1 infection, caused mainly by Streptococcus pneumoniae and Staphylococcus aureus (4). In spite of performing an optimal ventilatory support, there may be a refractory hypoxemia and hypercapnia. In these patients, extracorporal membrane oxygenation (ECMO) can be an alternative management (3). However, the high mortality rates in the reported ECMO series led to the loss of hopes that raised by this technique. Hypotension requiring vasopressor treatment and acute renal failure are the main complications in H1N1 patients in ICU $(40,41)$. Patients with severe illness die from secondary multiorgan insufficiencies caused by severe hypoxemia and hypotension. Recent investigations reported that the current severity scores of community acquired pneumonia (CURB-65 and pneumonia severity index) could not estimate the mortality in many hospitalized patients $(42,43)$.

According to this study, there were statistically significant features between survivors and nonsurvivors regarding the success of noninvasive ventilation (NIV) in the view of time to confirmation of the H1N1 virus infection after hospital admission, and $\mathrm{PaO}_{2} / \mathrm{FiO}_{2}$ ratio. Failure of NIV, late diagnosis, and a late onset to antiviral therapy would contribute to mortality (43). Children receiving chemotherapy and with immunosppressive condition have a higher mortality rates (44). In Table 3, the main predictors of mortality are reported.

\section{TABLE 3}

\section{Predictors of mortality}

- $\quad$ Late diagnosis after the symptoms $(7.2 \pm 3.8 \mathrm{~d})$

- Late onset to oseltamivir therapy (>48 h)

- Altered mental state

- Respiratory failure (dyspnea, cyanosis, a respiratory rate $\geq 30$ )

- Morbid obesity (body mass index $>40 \mathrm{~kg} / \mathrm{m}^{2}$ ) 
- Strong ion gap, acid-base disturbance

- Immunosuppression and chemotherapy (malignancy)

- Increased extent of pulmonary infiltrate on follow-up chest $x$-ray $>50 \%$

- High APACHE II Score at admission( $>21$ )

- Noninvasive ventilation failure $\left(\mathrm{PaO}_{2} / \mathrm{FiO}_{2}<140\right.$, arterial $\mathrm{pH}<7.31$, SOFA $\left.>5.1\right)$

The mortality rates were reported between 2.7-11\% in various studies and they were found higher in the patients who required mechanical ventilation and aged 50 or older $(28,45,46)$. During the postpandemic period, particularly elderly patients and the ones with chronic comorbidities mostly affected by influenza $A$ (H1N1) virus (47). Severe complications of the disease are worsening of underlying chronic disease (e.g. asthma, chronic obstructive pulmonary disease and heart failure), progressive pulmonary infection, acute respiratory distress syndrome with refractory hypoxemia, severe bacterial coinfection, septic shock, acute kidney failure, multiple organ failure, myocarditis and encephalitis.

\section{DIAGNOSIS}

Clinical diagnosis in the context of local influenza activity should inform treatment initiation. Monto et al. suggested a simple diagnostic hypothesis with a $79 \%$ positive predictive value, during an influenza epidemics the patients presenting with both cough and fever $\left(>38{ }^{\circ} \mathrm{C}\right)$ within the first 48 hours of symptom onset are very likely to have actual influenza (50). Nasopharyngeal aspirates or swabs should be taken to identify the virus and to confirme definite diagnosis after the onset of symptoms. Endotracheal or bronchoscopic aspirates have higher diagnostic yields in patients with lower respiratory tract illness.

The gold standard diagnostic test is the virus culture but the results can be obtained after several days (23). The real-time reverse transcriptase-polymerase chain reaction ( $r R T$ PCR) swine flu panel is a fast and reliable diagnostic test and used for detection of pandemic influenza A H1N1 strain $(35,48)$. The direct fluorescent antigen influenza test is another diagnostic assay with a sensitivity of $93 \%$, requires experienced technical persons and fluorescent microscope (49). A negative result of any rapid diagnostic test cannot exclude the diagnosis of influenza infection in a clinical or epidemiological suspicion, during a pandemic and if initial tests are negative for influenza A H1N1 virus, diagnostic tests should be repeated within 2-3 days.

\section{MANAGEMENT}

Clinical triage algorithms for H1N1 pneumonia according to the WHO recommendation is shown in Table 4 (2). Most of the patients with influenza A H1N1 infection recover without any severe complication. Supportive treatments such as non-steroidal anti-inflammatory drugs (e.g. paracetamol) for the relief of fever and pain, fluid rehydration can be provided. Aspirin may cause Reye's syndrome in children with influenza infection and should be avoided.

Influenza A (H1N1) virus is resistant to the M2 inhibitor antiviral drugs (amantadine and rimantadine) but it is susceptible to neuraminidase inhibitors (oseltamivir and zanamivir) in most of the cases. Sporadic oseltamivir resistance has been reported (28). Early oseltamivir therapy can shorten the duration of symptoms; for high-risk patients or progressive clinical illness, oseltamivir or zanamivir should be initiated within $48 \mathrm{~h}$ of the onset of disease $(28,51)$. The recommended standard dose of oseltamivir is $75 \mathrm{mg}$ twice daily for 5 days for adults and $3 \mathrm{mg} / \mathrm{kg}$ twice daily for 5 days for children 6 to 12 months of age. In severe cases oseltamivir treatment is recommended in higher doses as twice $150 \mathrm{mg}$ 
daily at least 10 days (51). The recommended dose of Zanamivir for adults and children ( $>5$ years) is twice $5 \mathrm{mg}$ inhalations daily for 5 days, for influenza treatment.

Antimicrobial treatment should follow the recommendations of IDSA/ATS CAP guidelines if any pathogen(s) are present: use a betalactam plus either macrolide or a respiratory fluroquinolon (48). The use of vancomycin and linezolid against methicillin-resistant $S$. aureus should be limited to patients with a compatible clinical presentation such as shock and necrotizing pneumonia in intensive care units or microbiologically confirmed infection $(38,39)$. Corticosteroid treatment is controversial in influenza infections. Long term and high dose use of systemic corticosteroids may cause some complications such as fungal infections (e.g. invasive aspergillosis). On the other hand, low doses of systemic corticosteroids and vasopressor agents may be considered in septic shock. Arterial blood oxygen saturation levels $\left(\mathrm{SaO}_{2}\right)$ should be kept over $90 \%$ (92-95\% for the pregnant), with additional oxygen via nasal cannula or mask (52). Infants are in risk group to have a severe illness and arterial oxygenations may be impaired quietly so the physicians should be careful. Blood pressure and pulse rate levels should be closely monitored in acute lung injury and acute respiratory distress syndrome. Intravascular fluid and electrolyte balance may be impaired during systemic inflammation, the essential volume supplementations should be maintained.

\section{MECHANICAL VENTILATION}

Mechanical ventilation is needed as a general treatment modality in most of the patients with influenza A H1N1 pneumonia. An ideal protective mechanical ventilation strategy with a tidal volume lower than $6 \mathrm{~mL} / \mathrm{kg}$ and with a lower plateau pressure than $30 \mathrm{cmH}_{2} \mathrm{O}$ can increase survivals (53). Additionally, Boots et al. successfully used some alternative ventilation modes such as high frequency oscillatory and airway pressure release ventilation in severe hypoxemic patients during the 2009 H1N1 influenza pandemic in Australia and New Zealand (52). When an outbreak of H1N1 respiratory illness started, several investigations stated that mechanical ventilation failed to recover the disease (13,31,53-57). However, recent studies have reported the effectiveness of NIV in some of the cases with severe respiratory failure related to H1N1 pneumonia and early mechanical ventilation was strongly recommended $(13,56,57)$. In some of the cases with H1N1 pneumonia and severe respiratory failure, an optimal arterial blood oxygen saturation level (> 90\%) cannot be maintained by noninvasive or even by invasive mechanical ventilation. The method of extracorporal membrane oxygenation (ECMO) is an alternative but the survival results are controversial (57-60). 
Table 4: Clinical triage algorithms for H1N1 pneumonia (risk factors was shown in Table 1)

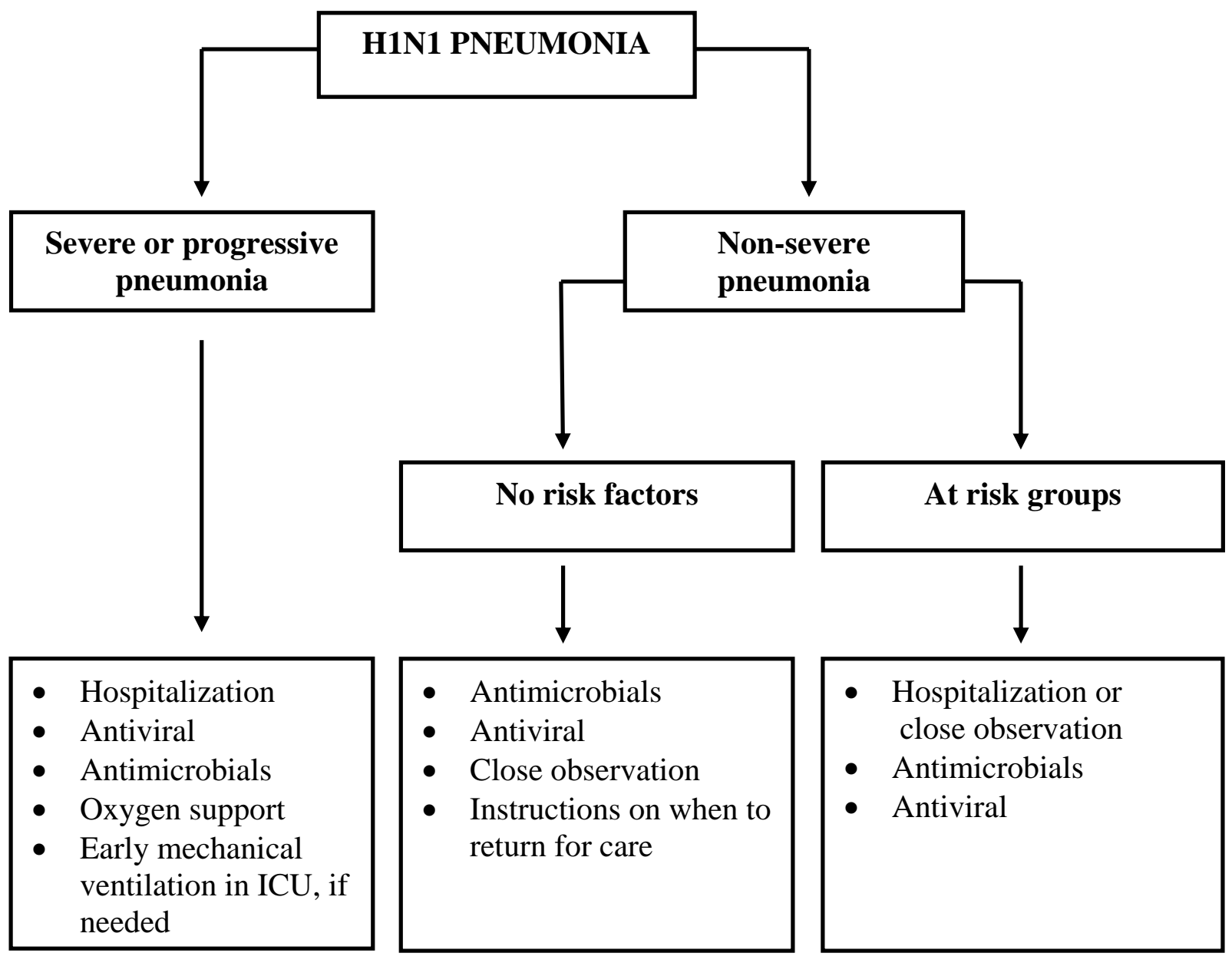

\section{INFECTION CONTROL}

Vaccination is the best protection method during a viral pandemic. During a pandemic period, health care providers should be obligated to follow the WHO guidance of standard and droplet infection control methods and patients with respiratory symptoms should be strongly encouraged for using protective masks, washing hands with soap and disposing of any infected wastes (61). Whenever performing bronchoscopy or any high risk aerosol-generating procedures involving aspiration of the respiratory tract, a particulate respirator (N95, FFP2 or equivalent), eye protection, gowns, and gloves should be used, and the procedures should be carried out in an adequately ventilated room. Special attention is recommended for health care providers of immunosuppressive patients who may shed virus for a longer time period ( $>7$ days) and are also at increased risk for development of antiviral-resistant virus.

\section{CONCLUSIONS}

Influenza A (H1N1) virus causes a higher incidence of severe pneumonia compared with other viruses and seasonal influenza. Several preexisting conditions such as obesity, pregnancy, chronic cardiopulmonary disease, diabetes mellitus, neurological disabilities predispose to disease severity. Early oseltamivir therapy can shorten the duration of symptoms; for high-risk patients or progressive clinical illness, oseltamivir or zanamivir should be initiated within $48 \mathrm{~h}$ of the onset of disease. In cases with severe H1N1 pneumonia accompanying with bacterial coinfection; an 
appropriate antimicrobial treatment, early Conflicts of interest

onset of oxygenation and mechanical The authors declare that there are no conflicts ventilatory support can decrease the mortality of interest. rate. Delays in diagnosis and medical care may increase the mortality.

\section{References}

1. Chowell G, Bertozzi SM, Colchero MA, Lopez-Gatell H, Alpuche-Aranda C, Hernandez M, Miller MA. Severe respiratory disease concurrent with the circulation of H1N1 influenza. N Engl J Med. 2009;361(7):674-679. doi:10.1056/NEJMoa0904023.

2. World Health Organization (WHO), 2009. Outbreak of swine origin influenza A (H1N1) virus infection-Mexico, March-April 2009. http//www.who.int, MMWR Morb Mortal Wkly Rep. 58, 467. September 2011.

3.Combes A, Pellegrino V. Extracorporeal membrane oxygenation for 2009 influenza A (H1N1)-associated acute respiratory distress syndrome. Semin Respir Crit Care Med. 2011;32(2):188-194.

4.Centers for Disease Control and Prevention (CDC). Bacterial coinfections in lung tissue specimens from fatal cases of 2009 pandemic influenza A (H1N1) - United States, May-August 2009. MMWR Morb Mortal Wkly Rep 2009; 58: 1071-1074.

5.Gong MN, Bajwa E, Thompson BT, Christiani DC. Body mass index is associated with the development of acute respiratory distress syndrome. Thorax 2010;65:44-50.

6. Li M, Zhu JB, Chen GQ, Yang WY, Tao C, Wang XH. Influenza A (H1N1) pneumonia: an analysis of 63 cases by chest CT. Chin Med J (EngI). 2011;124(17):2669-2673.

7. Valente T, Lassandro F, Marino M, Squillante F, Aliperta M, Muto R. H1N1 pneumonia: our experience in 50 patients with a severe clinical course of novel swine-origin influenza A (H1N1) virus (S-OIV). Radiol Med. 2012;117(2):165-184. doi: 10.1007/s11547-011-0734-1.

8. Riquelme R, Torres A, Rioseco ML, et al. Influenza pneumonia: a comparison between seasonal influenza virus and the H1N1 pandemic. Eur Respir J. 2011;38:106-111.

9. Chan PA, Mermel LA, Andrea SB, McCulloh R, Mills JP, Echenique I, et al. Distinguishing characteristics between pandemic 2009-2010 influenza A (H1N1) and other viruses in patients hospitalized with respiratory illness. PLoS One. 2011;6(9):e24734. doi: 10.1371/journal.pone.0024734.

10. Fabbiani M, Sali M, Di Cristo V, Pignataro G, Prete V, Farina S, et al. Prospective evaluation of epidemiological, clinical, and microbiological features of pandemic influenza A (H1N1) virus infection in Italy. J Med Virol.

2011;83(12):2057-2065. doi: 10.1002/jmv.22231.

11. Dhanoa A, Fang NC, Hassan SS, Kaniappan P, Rajasekaram G. Epidemiology and clinical characteristics of hospitalized patients with pandemic influenza A (H1N1) 2009 infections: the effects of bacterial coinfection. Virol J. 2011;8:501. doi: 10.1186/1743-422X-8-501.

12. Novel Swine-Origin Influenza A (H1N1) Virus Investigation Team, Dawood FS, Jain S, Finelli L, Shaw MW, Lindstrom S, Garten RJ, Gubareva LV, Xu X, Bridges CB, Uyeki TM: Emergence of a novel swine-origin influenza A (H1N1) virus in humans. N Engl J Med 2009, 360:2605-2615.

13. Djibre M, Berkane N, Salengro A, Ferrand E, Denis M, Chalumeau-Lemoine L, et al. Non-invasive management of acute respiratory distress syndrome related to Influenza $A(H 1 N 1)$ virus pneumonia in a pregnant woman. Intensive Care Med. 2010;36(2):373-374. doi: 10.1007/s00134-009-1684-0.

14.Marcos MA, Esperatti M, Torres A. Viral pneumonia. Curr Opin Infect Dis. 2009;22:143-147.

15.Nicolini A., Cilloniz C., Cuenca E., Torres A. Influenza A (H1N1) Pneumonia: A Review and Update. Clinical Pulmonary Medicine, 2012;19(6), 246-253.

16. Cunha BA. Swine influenza (H1N1) pneumonia: clinical considerations. Infect Dis Clin North Am. 2010;24:203-228.

17. Lat A, Bhadelia N, Miko B, Furuya EY, Thompson GR 3rd. Invasive aspergillosis

after pandemic (H1N1) 2009. Emerg Infect Dis. 2010;16(6):971-973. doi: 10.3201/eid1606.100165.

18. Cunha BA, Syed U, Strollo S. Non-specific laboratory test indicators of severity in hospitalized adults with swine influenza (H1N1) pneumonia. Eur J Clin Microbiol Infect Dis. 2010;29:1583-1588.

19. Cunha BA, Pherez FM, Schoch P. Diagnostic importance of relative lymphopenia as a marker of swine influenza (H1N1) in adults. Clin Infect Dis. 2009;49:1454-1456. 
20. Dye JA, Adler KB. Effects of cigarette smoke on epithelial cells of the respiratory tract. Thorax 1994, 49:825-834.

21. Puchelle E, Zahm JM, Bertrand A. Influence of age on bronchial mucociliary transport. Scand J Respir Dis 1979;60:307-313.

22. Bender BS, Small PA Jr. Influenza: pathogenesis and host defense. Semin Respir Infect 1992;7:38-45.

23. Treanor JJ. Influenza virus. In Principles and Practice of Infectious Disease. Vol. 2. Edited by Mandell G, Bennett JE, Dolin R. Philadelphia, PA: Churchill Livingstone; 2005:2060.

24. Walsh JJ, Dietlein LF, Low FN, Burch GE, Mogabgab WJ. Bronchotracheal response in human influenza. Type A, Asian strain, as studied by light and electron microscopic examination of bronchoscopic biopsies. Arch Intern Med 1961, 108: 376-388.

25. Oseasohn R, Adelson L, Kaji M. Clinicopathologic study of thirty-three fatal cases of Asian influenza. N Engl J Med 1959, 260:509-518.

26. Louria DB, Blumenfeld HL, Ellis JT, Kilbourne ED, Rogers DE. Studies on influenza in the pandemic of 1957-1958. II. Pulmonary complications of influenza. J Clin Invest 1959, 38(1Part 2):213-265.

27. Capelozzi VL, Parra ER, Ximenes M, Bammann RH, Barbas CS, Duarte MI. Pathological and ultrastructural analysis of surgical lung biopsies in patients with swine-origin influenza type A/H1N1 and acute respiratory failure. Clinics (Sao Paulo). 2010;65(12):1229-1237.

28. Bai L, Cao B, Wang C. Influenza A pandemic (H1N1) 2009 virus infection. Chin Med J (Engl). 2011;124:3399-3402. 29. Yamada K, Shinmoto H, Hamamoto M, Yoshida Y, Kawauchi T, Kaji T, et al. Pneumonia induced by swine-origin influenza A (H1N1) infection: chest computed tomography findings in children. Jpn J Radiol. 2011 Dec;29(10):712-717. doi: 10.1007/s11604-011-0620-8.

30. Shaham D, Bogot NR, Aviram G, Guralnik L, Lieberman S, Copel L, et al. Severe influenza A (H1N1): the course of imaging findings. Isr Med Assoc J. 2011;13(10):591-596.

31. Perez-Padilla R, de la Rosa-Zamboni D, Ponce de Leon S, Hernandez M, Quinones-Falconi F, Bautista E, et al. Pneumonia and respiratory failure from swine-origin influenza A (H1N1) in Mexico. N Engl J Med. 2009;361(7):680689.

32. Aviram G, Bar-Shai A, Sosna J, Rogowski O, Rosen G, Weinstein I, Steinvil A, Zimmerman O. H1N1 influenza: initial chest radiographic findings in helping predict patient outcome. Radiology. 2010 ;255(1):252-259.

doi:10.1148/radiol.10092240.

33. Marcos MA, Ramon S, Anton A, Martinez E, Vilella A, Olive V, et al. Clinical relevance of mixed respiratory viral infections in adults with influenza A H1N1. Eur Respir J. 2011;38(3):739-742. doi: 10.1183/09031936.00168610. 34. Nisii C, Meschi S, Selleri M, Bordi L, Castilletti C, Valli MB, et al. Frequency of detection of upper respiratory tract viruses in patients tested for pandemic H1N1/09 viral infection. J Clin Microbiol. 2010;48(9):3383-3385.

doi:10.1128/JCM.01179-10.

35. Renois F, Talmud D, Huguenin A, Moutte L, Strady C, Cousson J, et al. Rapid detection of respiratory tract viral infections and coinfections in patients with influenza-like illnesses by use of reverse transcription-PCR DNA microarray systems. J Clin Microbiol. 2010;48(11):3836-3842. doi: 10.1128/JCM.00733-10.

36. Viasus D, Pano-Pardo JR, Pachon J, Campins A, Lopez-Medrano F, Villoslada A, et al. Novel Influenza A (H1N1)

Study Group of the Spanish Network for Research in Infectious Diseases (REIPI). Factors associated with severe disease in hospitalized adults with pandemic (H1N1) 2009 in Spain. Clin Microbiol Infect. 2011;17(5):738-46. doi:

$10.1111 / j .1469-0691.2010 .03362$

37. Koon K, Sanders CM, Green J, Malone L, White H, Zayas D, et al. Co-detection of pandemic (H1N1) 2009 virus and other respiratory pathogens. Emerg Infect Dis. 2010;16(12):1976-1978. doi: 10.3201/eid1612.091697.

38. Hayashi Y, Vaska VL, Baba H, Nimmo GR, Davis L, Paterson DL. Influenza-associated bacterial pathogens in patients with 2009 influenza A (H1N1) infection: impact of community-associated methicillin-resistant Staphylococcus aureus in Queensland, Australia. Intern Med J. 2012;42(7):755-760. doi: 10.1111/j.1445-5994.2011.02602.x.

39. Murray RJ, Robinson JO, White JN, Hughes F, Coombs GW, Pearson JC, et al. Community-acquired pneumonia due to pandemic $A(H 1 N 1) 2009$ influenzavirus and methicillin resistant Staphylococcus aureus co-infection. PLoS One. 2010;5(1):e8705. doi: 10.1371/journal.pone.0008705.

40. Rello J, Rodriguez A, Ibanez P, Socias L, Cebrian J, Marques A, et al. H1N1 SEMICYUC Working Group. Intensive care adult patients with severe respiratory failure caused by Influenza A (H1N1)v in Spain. Crit Care. 2009;13(5):R148. doi: $10.1186 /$ cc8044.

41. Miller RR 3rd, Markewitz BA, Rolfs RT, Brown SM, Dascomb KK, Grissom CK ,et al. Clinical findings and demographic factors associated with ICU admission in Utah due to novel 2009 influenza A(H1N1) infection. Chest. 2010 Apr;137(4):752-758. doi: 10.1378/chest.09-2517. 
42. Riquelme R, Jimenez P, Videla AJ, Lopez H, Chalmers J, Singanayagam A, et al. Predicting mortality in hospitalized patients with 2009 H1N1 influenza pneumonia. Int J Tuberc Lung Dis. 2011;15(4):542-546. doi: 10.5588/ijtld.10.0539. 43. Kirakli C, Tatar D, Cimen P, Edipoglu O, Coskun M, Celikten E, et al. Survival from severe pandemic H1N1 in urban and rural Turkey: a case series. Respir Care. 2011;56(6):790-795.

44. Elbahlawan L, Gaur AH, Furman W, Jeha S, Woods T, Norris A, et al. Severe H1N1-associated acute respiratory failure in immunocompromised children. Pediatr Blood Cancer. 2011;57(4):625-628. doi: 10.1002/pbc.22973.

45. Louie JK, Acosta M, Winter K, Jean C, Gavali S, Schechter R, et al.; California Pandemic (H1N1) Working Group. Factors associated with death or hospitalization due to pandemic 2009 influenza A(H1N1) infection in California. JAMA. 2009;302(17):1896-1902. doi: 10.1001/jama.2009.1583.

46. Jain S, Kamimoto L, Bramley AM, Schmitz AM, Benoit SR, Louie J, et al. 2009 Pandemic Influenza A (H1N1) Virus Hospitalizations Investigation Team. Hospitalized patients with 2009 H1N1 influenza in the United States, April-June 2009. N Engl J Med. 2009;361(20):1935-1944. doi: 10.1056/NEJMoa0906695.

47. Martin-Loeches I, Díaz E, Vidaur L, Torres A, Laborda C, Granada R,et al. H1N1 SEMICYUC/REIPI/CIBERES Working group. Pandemic and post-pandemic influenza A (H1N1) infection in critically ill patients. Crit Care. 2011;15(6):R286. doi: $10.1186 /$ cc10573.

48. US Centers for Disease Control and Prevention: Interim guidance on specimen collection, processing, and testing for patients with suspected swine-origin influenza $A(H 1 N 1)$ virus infection

[http://www.cdc.gov/h1n1flu/specimencollection.htm].

49. Pollock NR, Duong S, Cheng A, Han LL, Smole S, Kirby JE. Ruling out novel H1N1 influenza virus infection with direct fluorescent antigen testing. Clin Infect Dis 2009, 49:e66-68.

50. Monto AS, Gravenstein S, Elliott M, Colopy M, Schweinle J. Clinical signs and symptoms predicting influenza infection. Arch Intern Med 2000, 160:3243-3247.

51. Hanshaoworakul W, Simmerman JM, Narueponjirakul U, Sanasuttipun W, Shinde V, Kaewchana S, et al. Severe human influenza infections in Thailand: oseltamivir treatment and risk factors for fatal outcome. PLoS One.

2009;4(6):e6051. doi: 10.1371/journal.pone.000605.

52. Boots RJ, Lipman J, Lassig-Smith M, Stephens DP, Thomas J, Shehabi Y,et al. Experience with high frequency oscillation ventilation during the $2009 \mathrm{H} 1 \mathrm{~N} 1$ influenza pandemic in Australia and New Zealand. Anaesth Intensive Care. 2011;39(5):837-46.

53. Ramsey CD, Funk D, Miller RR 3rd, Kumar A. Ventilator management for hypoxemic respiratory failure attributable to H1N1 novel swine origin influenza virus. Crit Care Med. 2010 Apr;38(4 Suppl):e58-65. doi:

10.1097/CCM.0b013e3181cde600.

54. Hui DS, Lee N, Chan PK. Clinical management of pandemic 2009 influenza A (H1N1) infection. Chest. 2010;137:916-925.

55. Kaufman MA, Duke GJ, McGain F, French C, Aboltins C, Lane G, Gutteridge GA. Life-threatening respiratory failure from H1N1 influenza 09 (human swine influenza). Med J Aust. 2009;191(3):154-6.

56. Patel M, Dennis A, Flutter C, Khan Z. Pandemic (H1N1) 2009 influenza. Br J Anaesth. 2010 Feb;104(2):128-42. doi: 10.1093/bja/aep375.

57. Winck JC, Marinho A. Non-invasive ventilation in acute respiratory failure related to 2009 pandemic influenza A/H1N1 virus infection. Crit Care. 2010;104:128-142.

58. MacLaren G, Combes A, Bartlett RH. Contemporary extracorporeal membrane oxygenation for adult respiratory failure: life support in the new era. Intensive Care Med. 2012;38:210-220.

59. Australia and New Zealand Extracorporeal Membrane Oxygenation (ANZ ECMO) Influenza Investigators, Davies A, Jones D, Bailey M, Beca J, Bellomo R, Blackwell N, et al. Extracorporeal Membrane Oxygenation for 2009 Influenza A(H1N1) Acute Respiratory Distress Syndrome. JAMA. 2009 Nov 4;302(17):1888-95. doi: 10.1001/jama.2009.1535. 60. Noah MA, Peek GJ, Finney SJ, Griffiths MJ, Harrison DA, Grieve R, et al. Referral to an extracorporeal membrane oxygenation center and mortality among patients with severe 2009 influenza A(H1N1). JAMA. 201;306(15):1659-68. doi: 10.1001/jama.2011.1471.

61. World Health Organization. Available from:http://www.who.int/csr/resources/ publications/infection_control/en/index.html. 04. p. 10-35 [In Greek]. 